\section{PROTECTIVE EFFECT OF ANTIMALARIALS ON THE RISK OF DAMAGE ACCRUAL IN SYSTEMIC LUPUS ERYTHEMATOSUS}

${ }^{1} \mathrm{G}$ Pons-Estel ${ }^{*},{ }^{2} \mathrm{D}$ Wojdyla, ${ }^{3} \mathrm{M}$ Ugarte-Gil, ${ }^{4} \mathrm{~F}$ Caeiro, ${ }^{5} \mathrm{E}$ Soriano, ${ }^{6} \mathrm{M}$ García, ${ }^{7} \mathrm{C}$ Drenkard, ${ }^{8} \mathrm{G}$ Berbotto, ${ }^{9} \mathrm{E}$ Bonfa, ${ }^{10} \mathrm{G}$ Vazquez, ${ }^{11} \mathrm{~L}$ Massardo, ${ }^{12} \mathrm{M}$ Guibert-Toledano, ${ }^{13} \mathrm{~V}$ PascualRamos, ${ }^{14} \mathrm{~L}$ Barile-Fabris, ${ }^{15}$ I García De La Torre, ${ }^{1}$ RM Serrano, ${ }^{16}$ M.I. Segami, ${ }^{17}$ J Gomez Puerta, ${ }^{18} \mathrm{G}$ Alarcón, ${ }^{19} \mathrm{~B}$ Pons-Estel. ${ }^{1}$ Institut Clínic de Medicina i Dermatologia- BarcelonaSpain, of Autoimmune Diseases, Barcelona, Spain; 'Universidad Nacional de Rosario, Estadistica, Rosario, Argentina; ${ }^{3}$ Hospital Guillermo Almenara Irigoyen. EsSalud, Rheumatology, Lima, Peru; ${ }^{4}$ Hospital Privado- Córdoba, Servicio de Reumatología, Cordoba Argentina; ${ }^{5}$ Hospital Italiano de Buenos Aires, Sección de Reumatología, Buenos Aires, Argentina; ${ }^{6}$ Hospital Interzonal General de Agudos General San Martín, Reumatología, La Plata, Argentina; ${ }^{7}$ Emory School of Medicine, Division of Rheumatology, Atlanta, USA ${ }^{8}$ Hospital Escuela Eva Perón, Reumatología, Granadero Baigorria, Argentina; ${ }^{9}$ Hospital das Clínicas da Faculdade de Medicina da Universidade de São Paulo, Rheumatology, São Pablo, Brazil; ${ }^{10}$ Universidad de Antioquia- Hospital Universitario- Fundación San VicenteMedellin, Reumatología, Medellin, Colombia; ${ }^{11}$ School of Medicine- Pontificia Universidad Católica de Chile, of Clinical Immunology and Rheumatology, Santiago, Chile; ${ }^{12}$ Centro de Investigaciones Médico Quirúrgicas CIMEQ, Servicio Nacional de Reumatología-, La Habana, Cuba; ${ }^{13}$ Instituto Nacional de Ciencias Médicas y Nutrición Salvador Zubirán, Immunology and Rheumatology, México city, Mexico; ${ }^{14}$ Hospital de Especialidades- Centro Médico Nacional Siglo XXI-Instituto Mexicano del Seguro Social, Clínico de Reumatología, Ciudad de México, Mexico; ${ }^{15}$ Hospital General de Occidente and Universidad de Guadalajara, Department of Immunology and Rheumatology, Guadalajara, Mexico; ${ }^{16}$ Universidad Nacional Mayor de San Marcos- Lima- Perú Servicio de Reumatología- Hospital Nacional Edgardo Rebagliati Martins- EsSalud- Lima- Perú, Reumatología, Lima, Peru; ${ }^{17}$ University of Antioquia- Medellin, Rheumatology, Medellin, Colombia; ${ }^{18}$ The University of Alabama at Birmingham, of Medicine- Division of Clinical Immunology and Rheumatology, Birmingham, USA; ${ }^{19}$ Hospital Provincial de Rosario, Rheumatology, Rosario, Argentina

\subsection{6/lupus-2017-000215.192}

Background and aims Antimalarials (AMs) have been shown to exert a reduced risk of damage accrual in North American and European SLE patients. We are presenting data from Latin American patients.

Methods Patients with a recent SLE diagnosis ( $\leq 2$ years) from the GLADEL cohort were studied. End-point: Increase in damage (SLICC Damage Index, SDI) since cohort entry.

Independent (socio-demographic, clinical laboratory and treatment) variables were included. The effect of AMs use on damage (adjusting for potential confounders) was examined with a multivariable Cox regression model with a stepwise selection algorithm (variables retained in the model $\alpha$ : 0.05 ). AMs was a time-dependent variable (user: patient receiving AMs during the previous 30 days) in the regression model.

Results Of the 1466 patients included in this analysis 1049 (72\%) received AMs during follow-up (as defined); median exposure time: 30 months (Q1-Q3: 11-57 months). Damage accrual occurred in 665 (45\%) patients during a median follow up time of 24 months (Q1-Q3: 8-55) months. After adjusting for potential confounders (SDI at cohort entry, socioeconomic status, disease duration at cohort entry, malar rash, photosensitivity, serositis, oral glucocorticoids, pulse glucocorticoids and SLEDAI at cohort entry) at any time during followup, a patient on AMs had a 25\% lower risk of damage accrual than a patient not on AMs (adjusted HR 0.75, 95\% CI 0.62-0.90).

Conclusions After adjustment for possible confounding factors related to AMs use and damage accrual, AMs were independently associated with a reduced risk of damage accrual in this cohort.

\section{3 MASSIVE PERICARDIAL EFFUSION IN YOUNG FEMALE OF SYSTEMIC LUPUS ERYTHEMATOSUS}

D.M. Rangkuti. Medan, Indonesia

\subsection{6/lupus-2017-000215.193}

Background and aims Systemic lupus erythematosus (SLE) is an autoimmune disease that has a variety of complications in all organs of the body. Pericardial effusion in the one manifestation SLE of the heart and an emergency nature. Massive pericardial effusion may result failure in cardiac pumping that is often referred to cardiac tamponade. Searching for the causes of pericardial effusion is required for diagnosis and therapy. Methods A woman, 19 years old with complaints of chest pain and shortness of breath. Pale, joint pain, fever and weight loss.

On examination found tachycardia, pallor, muffled heart sounds, bilateral pleural effusions, and pretibial oedema.

Laboratories: $\mathrm{Hb} 8.6 \mathrm{~g} / \mathrm{dl}$, leukocytes $5900 / \mathrm{mm}^{3}$, Ht 27.7\%, PLT $192,000 / \mathrm{mm}^{3}$, urea $97.9 \mathrm{mg} / \mathrm{dl}$, creatinine $1,51 \mathrm{mg} / \mathrm{dl}$, ferritin $>2000 \mathrm{ng} / \mathrm{ml}$, FE $17 \mathrm{mg} / \mathrm{dl}$, TIBC $103 \mathrm{ug} / \mathrm{dl}$, albumin $2.1 \mathrm{~g} / \mathrm{dl}, 68.9$ ANA test positive, Anti ds-DNA in 2754, CRP positive. Echocardiography showed massive pericardial effusion $\Phi 30.2 \mathrm{~mm}$. Fluid analysis : reddish colour, $\mathrm{pH} 7.9,0.178 \times$ $103 \mathrm{WBC} / \mathrm{uL}, 0.005 \times 106 \mathrm{RBC} / \mathrm{uL}, \mathrm{MN}$ cells $36 \%$, and 64\% PMN cells.

Diagnosed was done SLE with massive pericardial effusion.

Therapy: pulse steroids and mmf. Antibiotic, diuretic, ACEi, deferoxamine and antipyretic. Patients do pericardiasynthesis. Results After all therapy for 5 days of treatment, the patients showed clinical improvement where the shortness and chest pain were reduced, clinical symptoms improved, and pulse $90 \mathrm{x} / \mathrm{min}$. The patient is discharged with a follow-up plan every one moth.

Conclusions We reported a case of massive pericardial effusion young SLE patient. Patients receive immunosuppressive and also do pericardiasynthesis.

\section{RISK FACTORS FOR BACTEREMIA IN THAI PATIENTS WITH SYSTEMIC LUPUS ERYTHEMATOSUS}

B Siripaitoon*, P Intapiboon. Prince of Songkla University, Department of Internal Medicine, Songkhla, Thailand

\subsection{6/lupus-2017-000215.194}

Background and aims Bacteremia significantly affects mortality rate in SLE. It characterises differently across diverse geographic area. This study aimed to identify risk factors for bacteremia in Thai SLE patients.

Methods A retrospective case-control study recruited SLE patients who admitted between 2004 and 2014. Cases with significant bacteremia from microbiology database were matched with SLE diagnosis. Controls were SLE patients selected from the year of the matched case's hospital admission with a ratio of 1:4. The admissions for elective procedure or patients having prior bacteremia were excluded. Demography, clinical features, organ involvement, SLE disease activity score, and treatments in the 3 months prior to admission were reviewed.

Results Among 87 episodes of bacteremia occurred in 68 SLE patients, gram negative bacteremia was commonly found in 62 episodes (69.7\%). The most common organism was nontyphoidal Salmonella sp. (22 episodes, 25.3\%). Common sites 